\title{
DETERMINATION OF KEY SECTORS IN A REGIONAL ECONOMY THROUGH INPUT-OUTPUT ANALYSIS: \\ THE NORTH CENTRAL TEXAS CASE
}

P.M. Hayashi, W.E. Mullendore and A. L. Ekholm*

\section{INTRODUCTION}

Regional promoters and planners face the problem of how to achieve economic development. One possible way is to develop many sectors of the regional economy at the same time, and the other possible way is to develop a sector or few sectors of the economy which, in turn, stimulates other sectors of the economy. These different approaches, "the balanced growth" and "the unbalanced growth", are the basis for a well known controversy in the field of economic development.

Nurkse is one of the advocates of the balanced growth theory. ${ }^{1}$ According to Nurkse, investment in a single sector will not spur economic development and investment should be made in many sectors to be successful in economic development. On the other hand, Hirschman, who is a critic of the balanced growth theory, advocates the theory of unbalanced growth, He states:

In fact, development has of course proceeded inthis way with growth communicated from the leading sectors of the economy to the followers, from one industry to another, from one firm to a nother ... The advantage of this kind of seesaw advance over 'balanced growth, " where every activity expands perfectly in step with every other, is that it leaves considerable scope to induce investment decisions and therefore economizes our principle scarce resource, genuine decision-making. 2

Having advocated "unbalanced growth, "Hirschman then attempted to identify sectors which provide high stimulus to other sectors and to the growth of the economy. Such sectors a re called 'key sectors." Employing "the unbalanced growth theory" the task of the planner is toidentify key sectors for the economic development of a region. The purpose of this paper is twofold: one is to survey the methodologies foridentification of key sectors and the othe $r$ is to present and analyze the results of identifying key sectors for the North Central Texas Region.

\section{REVIEW OF METHODOLOGY FOR IDENTIFICATION OF KEY SECTORS}

To identify key sectors, it is necessary to trace relationships between a sector in question and the other sectors. If a self-sufficient sector is chosen by the planner the growth of this particular sector will not stimulate the growth of other sectors because it will not purchase inputs from other sectors and will not sell it's output to other sectors. Conversely, if a sector which purchases inputs fromother sectors and/or sells its output to other sectors is selected as a key sector, the growth of the sector increases the demand for inputs from other sectors and/orincreases the supply of its outputs to other sectors. The growth of this particular sector will have an impact on the growth of the regional economy. The relationships among sectors

* The authors are, respectively, Associate Professor of Economics, Associate Professor of Economics, and Instructor of Economics, The University of Texas at Arlington, 
are termed "linkages" and linkages are classified into two categories: forward linkages and backward linkages. Forward linkages stimulate the growth of sectors in subsequent stages of production, while backward linkages stimulate the growth of sectors in earlier stages of production. In the inputoutput table, moving down a column shows backward linkages and moving along a row shows forward linkages. If a sector produces a final consumption good, it is likely that the sector has a weak forward linkage and a weak backward linkage. In Hirschman's terms, a key sector is one which has the maximum combined (forward and backward) linkages.

Method 1

A simple method of measuring linkages is suggested by Chenery and Watanabe. Although this method is not designed for the selection of key sectors, it can be used to identify key sectors. ${ }^{3}$ They suggest two indices that are defined as follows: "For each sector, the extent of indirect use of factors will be measured by the ratio of purchasedinput $\left(U_{j}\right)$ to the value of total production $\left(X_{j}\right)$, which we call $u_{j}$...We will define a similar measure, $w_{i}=$ $\mathrm{W}_{\mathrm{i}} / \mathrm{Z}_{\mathrm{i}}$, to denote the ratio of intermediate to final demand for a given product. $" 4$

In terms of matrix notation

$$
\begin{array}{ll}
U_{j} & =\sum_{i=1} x_{i j} \\
x_{j} & =U_{j}+v_{j} \\
u_{j} & =U_{j} / X_{j} \\
w_{i} & =\sum_{j=1} x_{i j} \\
z_{i} & =w_{i}+Y_{i} \\
w_{i} & =w_{i} / Z_{i}
\end{array}
$$

The symbols are defined as:

$\mathrm{U}_{\mathrm{j}}=$ total purchases of input by sector $\mathrm{j}$

$x_{1 j}=$ the amount of transaction between sector $i$ and sector $j$

$\mathrm{V}_{\mathrm{j}}=$ total value added by sector $\mathrm{j}$

$\mathrm{W}_{\mathrm{i}}=$ total intermediate use by sector $\mathrm{i}$

$X_{j}=$ total output of sector $j$

$\mathrm{Y}_{\mathrm{i}}=$ the final demand of sector $\mathrm{i}$

$\mathrm{Z}_{\mathrm{i}}=$ total demand of sector $\mathrm{i}$

A sector with a high $u_{j}$ is considered to have a strong backward linkage because it purchases a la rge amount of inputs from other sectors in relation to its total output. Then, a sector with a high $w_{i}$ is said to have a strong forward linkage for it sells a large portion of output to other sectors as inputs. The task of the planner is to select the highest combined value of $u_{j}$ and $w_{j}$. 
The disadvantage of this method is that it only considers the direct relationship but not the indirect relationships among sectors.

\section{Method 2}

Another method of finding linkages is to use the inverted matrix of (I-A) where $I$ is the identity matrix and $A$ is the matrix of input-output coefficients. This inverted matrix includes not only the direct effect but also the indirect effect of a dollar of sales to final demand. A backward linkage is found by the column total which measures the total expansion of dollar output in all sectors as a result of a one dollar sale to final demand of a given sector. This is referred to as the output multiplier in the input-output analysis. A forward linkage is found by summing each row of the inverted matrix. The row total is the total expansion of sales by a given sector as a result of one dollar sales to the final demand for all sectors.

\section{Method 3}

A more sophisticated method of finding linkages is developed by Ras mussen. The inverted matrix of (I-A) is also essential to Rasmussen's approach. Let $\mathrm{Z}=(\mathrm{I}-\mathrm{A})^{-1}$ and $\mathrm{Z}_{\mathrm{ij}}$ be the characteristic elements in the inverted matrix (Z). To estimate the backwardlinkages for a sector we compute a column total $(Z \cdot j)$.

$$
Z_{j}=\sum_{i=1} Z_{i j} \quad(i=1,2, \ldots, m)
$$

For estimating the forward linkages for a sector, it is necessary to compute a row total $\left(\mathrm{Z}_{\mathrm{i}} \cdot\right)$.

$$
Z_{i} \cdot=\sum_{j=1} Z_{i j} \quad(j=1,2, \ldots, m)
$$

Then, the average for each sector is computed by dividing $Z_{j_{j}}$ and $Z_{i}$. by the number of sectors $(\mathrm{m})$.

$$
\begin{array}{ll}
\bar{Z}_{j}=\frac{1}{m} \sum_{i=1}^{m} Z_{i j} & (i=1,2, \ldots, m) \\
\bar{Z}_{i}=\frac{1}{m} \sum_{j=1}^{m} Z_{i j} & (j=1,2, \ldots, m)
\end{array}
$$

He explains $\bar{Z}$. j"as an estimate of the (direct and indirect) increase in output to be supplied by an industry chosen at random if final demand for the products of industry no. $j(j=1,2, \ldots, m)$ increases by one unit" 5 and $\bar{Z}_{i}$. "as an estimate of the increase in output to be supplied by industry no. $\mathrm{i}$ ( $\mathrm{i}=$ $1,2, \ldots, m)$ if the final demand for the product of an industry chosen at random is increased by one unit. 116

It is convenient to make intersectoral comparisons, if these averages are in common units. For this purpose, the overallaverage is used and is defined as:

$$
\overline{\bar{Z}}=\frac{1}{m^{2}} \cdot \sum_{i=1}^{m} \sum_{j=1}^{m} z_{i j} \quad(i=1,2, \ldots, m ; j=1,2, \ldots, m)
$$


From 3, 4 and 5, two sets of indices are computed:

$$
\begin{aligned}
& U_{j}=\overline{\bar{Z}}_{j} / \overline{\bar{Z}} \\
& U_{i}=\overline{\bar{Z}}_{i} \cdot / \overline{\bar{Z}}
\end{aligned}
$$

If $\bar{Z} \cdot j$ is greater than $\overline{\bar{Z}}, U{ }_{j}$ will be greater than one. This implies that sector $\mathrm{j}$ requires larger output of other sectors due to a one dolla $\mathrm{r}$ increase in the final demand of the jth sector in comparison with all sectors in general and vice versa for $U . j<1$. Rasmussen terms $U_{.} j_{\text {as }}$ "the power of dispersion," which can be interpreted as a measure of backward linkages. When $U_{i}$. is greater than one (i.e., $\bar{Z}_{i}$. is greater than $\overline{\bar{Z}}$ ), sector i will increase its output comparatively more than other sectors for one dollar increase in the final demand and vice versa for $U_{i} .<1$. Rasmussenterms $U_{i}$ as "the sensitivity of dispersion, " which can be interpreted as a measure of forward linkages.

The indices $U_{.} j_{j}$ and $U_{i}$. alone cannot be used for identifying key sectors. After all, U. $j$ and $U_{i}$. a re averages and are influenced by extremely high or extremely low values. To measure the variability of each column and each row, the standard deviation of each sector is computed.

$$
\begin{aligned}
& \text { S. }{ }_{j}=\sqrt{\frac{1}{m-1} \sum_{i=1}^{m}\left(z_{i j}-\bar{Z} \cdot{ }_{j}\right)^{2}} \quad(i=1,2, \ldots, m) \\
& S_{i}=\sqrt{\frac{1}{m-1} \sum_{j=1}^{m}\left(z_{i j}-\bar{z}_{i} \cdot\right)^{2}} \quad(j=1,2, \ldots, m)
\end{aligned}
$$

For the purpose of intersectoral comparisons, $S_{j}{ }_{j}$ and $S_{i}$. a re divided by $\bar{Z}$.j and $\bar{z}_{i}$. respectively.

$$
\begin{aligned}
& v \cdot{ }_{j}=S \cdot{ }_{j} / \bar{Z} \cdot{ }_{j} \\
& v_{i} \cdot=S_{i} \cdot / \bar{Z}_{i} .
\end{aligned}
$$

The indices $V$. and $V_{1}$. are the coefficients of variation. The interpretation of these indices is as follows:

V. ${ }_{j}$ is then interpreted as an index showing to what extent industry no.j d draws evenly on the system of industries or - in case of a relatively great value of the index - whether industry no. j draws onesidely on the system of industries.

$\mathrm{V}_{\mathrm{i}}$. is interpreted as an index showing to what extent that system of industries draws evenly on industry no. i or - in case of a relatively great value of the index - whether the system of industries draws one-sidely on industry no. i. 7

The task of the planner is to choose sectors with high $\mathrm{U}_{\mathrm{j}_{\mathrm{j}}}$ and $\mathrm{U}_{\mathrm{i}}$. and relatively low $\mathrm{V}_{\mathrm{j}}$ and $\mathrm{V}_{\mathrm{i}}$. as key sectors.

Method 4

The methods discussed previously assign equal importance to every sector. In reality, some sectors are more important than others. Rasmussen 8 and Hazari ${ }^{9}$ suggest weighting systems to give relative importance to vari- 
ous sectors. In this paper, Hazari's method is discussed.

According to Hazari, the planner has the objective function and chooses weights in accordance with his objective function. One of such weights is a proportion of the final demand of sector i to the total final demand.

$$
\mathrm{P}_{\mathrm{i}}=\mathrm{F}_{\mathrm{i}} / \sum_{\mathrm{i}=1}^{\mathrm{m}} \mathrm{F}_{\mathrm{i}} \quad(\mathrm{i}=1,2, \ldots, \mathrm{m})
$$

The symbols are defined as follows:

$$
\begin{aligned}
& P_{i}=\text { weight of sector } i \\
& F_{i}=\text { the final demand for sector } i
\end{aligned}
$$

To find the weighted indices, a column total $\left(Z_{j}\right)$ and a row total $\left(Z_{i} \cdot\right)$ are multiplied by the weight of the corresponding sector.

$$
\begin{aligned}
& \lambda_{j}=Z \cdot{ }_{j} P_{i} \\
& \lambda_{i}=Z_{i} \cdot P_{i}
\end{aligned}
$$

Interpretation of these indices is as follows:

Sectors in which both $\lambda_{j}$ and $\lambda_{i}$ are high can be defined as key sectors from the point of view of (a) the target of the planner implicit in the final demand sector and (b) the importance of each sector in the economy as a contributor to final demand. 10

The indices $\lambda_{j}$ and $\lambda_{i}$ provide us with weighted measures for identifying key sectors.

\section{THE EMPIRICAL RESULTS}

For the purpose of comparing the methods discussed in the previous section, the interindustry study of the North Central Texas region is used. The North Central Texas region includes 31 counties a round the Dallas-Fort Worth Metropolitan a rea and had a population of 3, 064, 560 in 1970. The input-output matrix contains 108 processing sectors: Agriculture-9, Mining2, Construction-5, Manufacturing-44, Transportation-7, Utilities and Communications -5 , Wholesale Trade -6 , Retail Trade-9, Finance, Insurance and Real Estate-3, and Services-18.

\section{The Results of Method 1}

From the transactions table which was constructed for the interindustry study of the North Central Texas Region, the ratio of purchased input to the

\begin{tabular}{|c|c|c|c|c|}
\hline Rank & Sector Name & $\mathrm{w}_{\mathrm{i}}$ & Rank & Sector Name \\
\hline 1 & Dairy & 89.7 & 1 & Feedlot livestock \\
\hline 2 & Ag. supply ex. mch. & 82.9 & 2 & Poultry \& eggs \\
\hline 3 & Cash grain & 81.7 & 3 & Dairy \\
\hline 4 & Adv., duplicating serv. & 78.9 & 4 & Dairy products \\
\hline
\end{tabular}
value of total production $\left(u_{j}\right)$ and the ratio of intermediate to final demand $\left(w_{i}\right)=$ are computed. Table 1 lists the top ten sectors ranked by the magnitude of $u_{j}$ and $w_{i}$.

Table 1. Top 10 Sectors Ranked by the Magnitude of $u_{j}$ and $w_{i}$ 
Table 1. Top 10 Sectors Ranked by the Magnitude of $u_{j}$ and $w_{i}$ Continued

\begin{tabular}{llclll} 
& \multicolumn{1}{c}{ Sector Name } & $Z_{j}$ & Rank & Sector Name & $Z_{i} \cdot$ \\
5 & Aircraft parts & 78.3 & 5 & Ag. Services & 47.0 \\
6 & Boxes \& papercontainers & 75.7 & 6 & Other electric appar. & 45.8 \\
7 & Feedlot livestock & 72.9 & 7 & Cotton & 45.6 \\
8 & Newspaper & 66.1 & 8 & F.I. R. E. & 41.6 \\
9 & Stone \& concrete prod. & 65.4 & 9 & Range livestock & 41.4 \\
10 & Poultry \& eggs & 72.3 & 10 & Cash grain & 40.7
\end{tabular}

Table 1 reveals that those sectors which purchase mainly from other sectors in the region and/or sell mainly to other sectors in the region are included in the topten lists. All top ten sectors ranked by $w_{i}$ sell more than 50 percent of their outputs locally and all top ten sectors ranked by $u_{j}$ purchase more than 40 percent of their inputs from the local processing sectors. Another noticeable feature of Table 1 is that agriculture sectorsappea $r$ to have strong forward $\left(w_{i}\right)$ and backward $\left(u_{j}\right)$ linkages.

The Results of Method 2

After the (I-A) matrix was inverted, sectors are ranked according to the magnitude of a row total $\left(Z_{i}\right)$ and a column total $\left(Z_{j}\right)$ in Table 2 .

Table 2. Top 10 Sectors Ranked by the Magnitude of $Z_{{ }_{j}}$ and $Z_{i}$.

\begin{tabular}{|c|c|c|c|c|c|}
\hline Rank & Sector Name & $\mathrm{Z} \cdot{ }_{\mathrm{j}}$ & Rank & Sector Name & $\mathrm{z}_{\mathrm{i}}$ \\
\hline 1 & Feedlot livestock & 2.16 & 1 & Banking \& credit & 2. 48 \\
\hline 2 & Poultry \& eggs & 2.07 & 2 & F.I.R.E. & 2.45 \\
\hline 3 & Dairy products & 1. 84 & 3 & Electric service & 2.28 \\
\hline 4 & Dairy & 1. 74 & 4 & Grain mill prod. & 2. 10 \\
\hline 5 & Ag. services & 1.63 & 5 & $\begin{array}{l}\text { Other chem \& allied } \\
\text { prod. }\end{array}$ & 2.06 \\
\hline 6 & Cotton & 1. 59 & 6 & General wholesale & 2.00 \\
\hline 7 & Range livestock & 1. 53 & 7 & Insurance carrier & 1.84 \\
\hline 8 & Other elec. appar. & 1.53 & 8 & Telephone \& telegraph & 1.80 \\
\hline 9 & F.I. R.E. & 1.51 & 9 & Maintainance \& repair & 1. 79 \\
\hline 10 & Lodging service & 1. 51 & 10 & Primary metal prod. & 1.77 \\
\hline
\end{tabular}

For backward linkages $\left(Z ._{j}\right)$, the agricultural sectors remain dominant. A Significant difference between Tables 1 and 2 show up in the forward linkages $\left(Z_{i} \cdot\right)$. These sectors which sell their outputs to a large number of the processing sectors in the region have strong forward linkages. When the direct and indirect effects of a one dollar sale to final demand a re considered, the results show that selling to a larger number of the processing sectors in the region produces stronger forward linkages than selling a large portion of output to the processing sectors in the region.

Next the household sector is included as a processing sector. The household sector supplies primary inputs, especially labor. Purchases of labor create forward linkages and backward linkages because households demand more goods and services due to higher incomes. Table 3 shows the top ten sectors ranked by a row total $\left(Z_{i}^{\prime} \cdot\right)$ and a column total $\left(Z_{j_{j}}^{\prime}\right)$ 


\begin{tabular}{|c|c|c|c|c|c|}
\hline Rank & Sector Name & $\mathrm{Z} !_{\mathrm{j}}$ & Rank & Sector Name & $\mathrm{Z}_{\mathrm{i}}^{\prime}$ \\
\hline 1 & Feedlot livestock & 2.47 & 1 & F.I.R.E. & 4.73 \\
\hline 2 & Poultry \& eggs & 2.33 & 2 & Insurance carrier & 3.67 \\
\hline 3 & Dairy products & 2.12 & 3 & Electric service & 3.59 \\
\hline 4 & Dairy & 2.05 & 4 & Banking \& credit agen. & 3.56 \\
\hline 5 & Cotton & 2.00 & 5 & Elem. \& sec. schools & 3.42 \\
\hline 6 & $\begin{array}{l}\text { Warehouse \& other } \\
\text { transportation }\end{array}$ & 1. 98 & 6 & Retail trade-general & 3.11 \\
\hline 7 & Ag. services & 1. 98 & 7 & Telephone \& telegraph & 2.73 \\
\hline 8 & Colleges \& univ. & 1.96 & 8 & Food products & 2.76 \\
\hline 9 & Range livestock & 1.93 & 9 & Maintenance \& repair & 2.72 \\
\hline 10 & Lodging service & 1.93 & 10 & Eating \& drinking places & 2.69 \\
\hline
\end{tabular}

The comparison of Tables 2 and 3 shows few changes in the top 10 sectors with forward $\left(Z_{i}{ }^{\prime}.\right)$ and backward $\left(Z{ }^{\prime}{ }_{j}\right)$ linkages. The colleges and universities sector and the elementary and secondary schools are included. They sell 79.2 percent and 63.6 percent of their output to households and purchase 70.1 percent and 78.2 percent of their gross outlays from households, respectively. Also, retail trade-general, food products, and eating and drinking places sell a large portion of their outputs to households. The addition of the household sector results in the sectors which have strong direct relationships with households being included in the top 10 sectors.

The Results of Method 3

Method 3 does not alter the ranking of the top 10 sectors by $U_{j_{j}}$ and $\mathrm{U}_{\mathrm{i}}$. from the results of method 2 as $\mathrm{Z}_{\mathrm{j}}$ and $\mathrm{Z}_{\mathrm{i}}$. a re divided by the same constant term. However, $V \cdot j$ and $V_{i}$. may show different rankings for the top 10 sectors. Tables 4 and 5 are based on the results of method 3 and sectors are ranked on the basis of the coefficient of variation. It appears that the ranking of the top 10 sectors by the coefficient of variation in all cases is fairly consistent with the ranking of the top 10 sectors by the power dispersion. The reason is that a high value for the power of dispersion of the sensitivity of dispersion implies that a sector depends heavily on other sectors. The coefficient of variation indicates whether a sector draws evenly on the system of industries or not. In the North Central Texas Region, sectors which depend heavily on other sectors (high U's) also tend to draw evenly on the system of industries (low V's).

The Results of Method 4

A percentage of the final demand of a sector to total final demand is used as the weight of each sector. Then, a column total and a row total are weighted by these percentages. Table 6 is the list of top 10 sectors ranked by $\lambda_{j}$ and $\lambda_{i}$.

The results of Method 4 alter substantially the results of other methods. There are three noticeable changes: (1) none of the agricultural sectors appears in the list; (2) three of five construction sectors in the model show strong backward and forward linkages; and (3) the most important sector in terms of total output--Aircraft, Aircraft Engines, and Ordnance--ranks at the top for both backward and forward linkages. This raises a question as to the weighting system employed. The Aircraft, Aircraft Engine, and Ordnance 
Table 4. Top 10 Sectors Ranked by $U_{j}$ and $V_{j}$ and $U_{i}$. and $V_{i}$.

(Households Exogenous)

\begin{tabular}{|c|c|c|c|c|c|c|c|}
\hline$\underset{1}{\text { Rank }}$ & Sector Name & $\mathrm{U}_{\mathrm{j}}$ & $\mathrm{V} \cdot{ }_{j}$ & Rank & Sectór Name & $\mathrm{U}_{\mathrm{i}}$ & $\mathrm{v}_{\mathrm{i}}$. \\
\hline 1 & Feedlot livestock & 1.73 & 5.4 & 1 & Banking \& credit & 1. 98 & 4.3 \\
\hline 2 & Poultry \& eggs & 1.65 & 5.8 & 1 & F.I. R.E. & 1. 98 & 4.3 \\
\hline 4 & Dairy products & 1. 48 & 6.3 & 3 & Electric service & 1.82 & 4.5 \\
\hline 3 & Dairy & 1.39 & 6.1 & 6 & Grain mill product & 1. 68 & 3. 5 \\
\hline 5 & Ag. services & 1. 30 & 6.5 & 5 & Other chemical prod. & 1.65 & 3. 4 \\
\hline 6 & Cotton & 1. 27 & 6.8 & 4 & General wholesale & 1. 60 & 5.2 \\
\hline 6 & Range livestock & 1.23 & 6.8 & 7 & Insurance carrier & 1. 47 & 5.6 \\
\hline 9 & Other elect. app. & 1. 22 & 7.0 & 8 & Telephone \& telegraph & 1. 44 & 5. 7 \\
\hline 10 & F.I.R.E. & 1.21 & 7. 1 & 9 & Maintenance \& repair & 1. 43 & 5.8 \\
\hline 8 & Lodging service & 1. 20 & 6.9 & 10 & Primary metal product & 1. 41 & 6. 1 \\
\hline
\end{tabular}

Table 5. Top 10 Sectors Ranked by $U .{ }_{j}$ and $V .{ }^{\prime}{ }$ and $U_{i}{ }^{\prime}$. and $V_{i}{ }^{\prime}$.

(Households Exogenous)

$\begin{array}{lll}\text { Feedlot livestock } & 1.53 & 4.7 \\ \text { Poultry \& eggs } & 1.45 & 5.1 \\ \text { Dairy products } & 1.32 & 5.5 \\ \text { Dairy } & 1.28 & 5.2 \\ \text { Cotton } & 1.24 & 5.4 \\ & & \\ \text { Warehouse-other tran. } & 1.23 & 5.3 \\ \text { Ag. services } & 1.23 & 5.3 \\ \text { Colleges \& univ. } & 1.22 & 5.4 \\ \text { Range livestock } & 1.20 & 5.4 \\ \text { Lodging service } & 1.20 & 5.4\end{array}$

7

5. 1

5. 5

5. 4

5.3

5. 3

5.4

5.4
F.I.R.E.

Insurance carrier

Electric services

Banking \& credit

Elem. \& sec. schools

2. 28

2. 23

2. 21

2. 12

1. 93

Retail trade-general

Telephone \& telegraph

Food products

1. 69

1. 71

1.69

Maintenance \& repair

Eating \& drinking Place 
Table 6. Top Sectors Ranked by $\lambda_{j}$ and $\lambda_{i}$

\begin{tabular}{|c|c|c|c|c|c|}
\hline Rank & Sector Name & ${ }^{\lambda}{ }_{j}$ & Rank & Sector Name & $\lambda_{\mathrm{i}}$ \\
\hline 1 & $\begin{array}{l}\text { Aircraft, aircraft eng. } \\
\text { \& ordnance }\end{array}$ & 16.78 & 1 & $\begin{array}{l}\text { Aircraft, aircraft eng. } \\
\text { \& ordnance }\end{array}$ & 14.91 \\
\hline 2 & Insurance carrier & 5.10 & 2 & Insurance carrier & 8.09 \\
\hline 3 & Facility construction & 4.57 & 3 & General wholesale & 6.21 \\
\hline 4 & Motor vehicles \& parts & 4.20 & 4 & Banking \& credit agen. & 6.21 \\
\hline 5 & $\begin{array}{l}\text { Comm., edu., \& indust. } \\
\text { \& construction }\end{array}$ & 4.05 & $\begin{array}{l}5 \\
6\end{array}$ & $\begin{array}{l}\text { F.I.R.E. } \\
\text { Motor vehicles \& parts }\end{array}$ & $\begin{array}{l}4.90 \\
4.68\end{array}$ \\
\hline 6 & Elect. comm. equip. & 4.03 & 7 & Elect. comm. equip. & 4.15 \\
\hline 7 & Food products & 3.95 & 8 & Facility construction & 3.79 \\
\hline 8 & Residential construction & 3.52 & $\dot{9}$ & Food Products & 3.59 \\
\hline 9 & General wholesale & 3.50 & 10 & Comm., edu., \& indust. & 3.23 \\
\hline 10 & F. I. R. E. & 3.02 & & construction & \\
\hline
\end{tabular}

sector is so large in relation to other sectors in final demand that it becomes the most important key sector, although it ranked 85 th and 101 st out of 108 sectors in terms of $\mathrm{Z}_{._{j}}$ and $\mathrm{Z}_{\mathrm{i}}$., respectively. Another question is the use of the same weight for both backward and forward linkages. It is permissible to weigh $Z_{j}$. by $P_{i}$ but it is desirable to use another weight for $Z$. $j$. One such weight is the ratio of value added by sector $\mathrm{j}$ to total value added. Despite these questions, the weighted indices appear to provide a meaningful measure for the planner, given his objective function.

\section{CONCLUSION}

Review of the methodology for identification of key sectors and the application of these methods to the North Central Texas economy indicate certain deficiences in the identification of key sectors. Hirschman points out one of the deficiencies in the idenfication of key sectors.

The ranking does an injustice to machinery and also to transport equipment. The low value of forward linkage in their case is probably due to the fact that sales of these industries to other industries are construed in input-output tables as final demand deliveries because they are accounted for under capital formation. 11

This injustice is also apparent in our analysis (Method 4 attempts to improve on this limitation as it weighs by final demand which includes sales to capital formation) and raises a valid criticism of the results. For short-run planning, capital formation can be treated as an exogenous sector. However, for long range planning of economic growth, capital formation should be integrated as an edogenous sector of the model in order to make the model dynamic rather than static. This improvement of the methodology by relating output changes to capital stock changes would indicate cause and effect relationships for regional growth that are not specified in the static model used in this paper.

The maximum combined linkage criteria results in the identification of key sectors that may be neither feasible nor desirable for the expansion of a regional economy. For example, in the results for North Central Texas, the agricultural sectors had strong combined linkages and were identified as key sectors in Methods 1-3. But the development of these agricultural sectors may be undesirable or nonfeasible in the North Central Texas case. 
The economist can provide useful information to planners with the key sector methodology but the planner must be cognizant of the limitations of each method. An interdisciplinary approach is necessary before key sector analysis can be applied by the planner. Input from the planner in the form of an objective function is necessary if the analysis is to be meaningful for a specific application. In Method 4, an objective function for the planner has been utilized in our analysis. By using final demand weights as a proxy for a planner's objective function, the Aircraft, Aircraft Engines, and Ordnance sector ranks first as a key sector. If the planner's goal is affluence in the region, this sector, consistent with export-base theory, is quite appropriate. However, if the planner's objective function incorporated a goal of cyclinal stability, one can expect an even different set of key sectors. Or, if the planner's objectives incorporated goals with regard to income distribution, further changes inkey sectors would be expected. In summary, though linkages, backward and forward, are important in the identification of key sectors, providing a role for the economist, further studies of key sectors, will provide applicable results as the planner and economist incorporate the goals of a region into the analysis. 


\section{FOOTNOTES}

${ }^{1}$ Ragnar Nurkse, Problems of Capital Formation in Underdeveloped Countries, Oxford University Press, New, York, 1960.

${ }^{2}$ Albert O. Hirschman, The Strategy of Economic Development, Yale University Press, New Haven, 1958, pp. 62-63.

3

Ibid., pp. 104-108.

${ }^{4} \mathrm{H} . \mathrm{B}$. Chenery and T. Watanebe "International Comparisions of the Structure of Production. "Econometrica, XXVI, No. 4, October 1958, p. 492.

${ }^{5}$ R. N. P. Rasmusşen, Studies in Inter-Sectoral Relations, NorthHollard Pub. Co., Amsterdam, 1952, p. 134.

${ }^{6}$ Ibid. , p. 134

7 Ibid., pp. 138-139.

${ }^{8}$ Ibid. , pp. $135-137$

${ }^{9}$ B. R. Hazari, "Empirical Identification of Key Sectors in the Indian Economy". The Review of Economics and Statistics, Vol. 52, No. 3, August 1970, pp. 301-305.

10 Ibid., p. 303.

${ }^{11}$ A. O. Hirschman, op. cit., p. 107. 